\title{
The Expression of Recombinant Human Serum Albumin in the Mammary Gland of Transgenic Mice
}

\author{
Gui-Hua Gong ${ }^{1}$ Shu Han ${ }^{1}$ Xiao-Ling Huang ${ }^{1}$ Li-Ping Xie ${ }^{1}$ Wei Zhang ${ }^{1}$ Lei Xu ${ }^{1}$ You-jia Hu ${ }^{1 *}$ \\ ${ }^{1}$ Biopharmaceutical Department, China State Institute of \\ Pharmaceutical Industry, Shanghai, People's Republic of China \\ Address for correspondence You-jia Hu, PhD, China State Institute of \\ Pharmaceutical Industry, 285 Gebaini Road, Shanghai 201203, \\ People's Republic of China (e-mail: bebydou@126.com).
}

Pharmaceut Fronts 2021;3:e30-e37.

\begin{abstract}
Human serum albumin (HSA) is widely used in the clinic for the treatment of several diseases in large amount each year. With the increasing demands of HSA in clinic and limited blood resource, recombinant HSA (rHSA) is becoming an attractive and alternative source for HSA production. In this study, we aimed to express rHSA in the mammary glands of transgenic mice by using a tissue-specific promoter and other regulatory elements. An rHSA expression vector was constructed bearing the cDNA and first intron of HSA under the control of bovine $\alpha_{51}$-casein promoter with a $2 \times$ chicken $\beta$ globin insulator in the front. Transgenic mice were generated and reverse transcription polymerase chain reaction showed that rHSA was expressed only in the mammary gland, indicating the tissue specificity of the bovine $\alpha_{s 1}$-casein promoter in directing

Keywords

- transgenic mice

- mammary gland

- recombinant human serum albumin transgene transcription in transgenic mice. Enzyme-linked immunosorbent assay test showed that rHSA was successfully secreted into the milk of transgenic mice with the highest level at $1.98 \pm 0.12 \mathrm{~g} / \mathrm{L}$. Our results indicate the ability of the bovine $\alpha_{\mathrm{s} 1}$-casein promoter to induce successful expression of rHSA in the mammary gland of transgenic mice.
\end{abstract}

\section{Introduction}

As the most abundant protein in human plasma, human serum albumin (HSA) has a single nonglycosylated polypeptide chain composed of 585 amino acids with a molecular weight of $66.5 \mathrm{kDa} .{ }^{1} \mathrm{HSA}$ is widely used in the clinic for the treatment of several diseases including shock, hemodialysis, surgical blood loss, acute respiratory distress syndrome, acute liver failure, and hypoalbuminemia. ${ }^{2}$ Moreover, HSA is used in various biotechnological applications such as fusion proteins, ligand trapping, surgical adhesives, and sealants. ${ }^{3-5}$ Clinically used HSA is normally derived from human plasma; therefore, there is a risk of infection from blood contamination such as human immunodeficiency virus and hepatitis viruses. As a result, recombinant HSA (rHSA) is considered as an alternative source of pathogenfree HSA for therapeutic applications. ${ }^{6}$

received

March 23, 2021

accepted

April 9, 2021
DOI https://doi.org/ $10.1055 / \mathrm{s}-0041-1730985$. ISSN 2628-5088.
rHSA has been produced in a variety of hosts, including bacteria, ${ }^{7}$ yeast, ${ }^{8}$ transgenic plants, ${ }^{9}$ and transgenic animals. ${ }^{10}$ The first approved rHSA for clinical use was Medway, produced by Mitsubishi Tanabe Pharmaceutical Co. However, it was withdrawn from the market in 2009. In 2005, another rHSA from Novozymes Inc. branded Recombumin was approved for use as pharmaceutical excipients. Both rHSA were produced by Saccharomyces cerevisiae containing an expression cassette with HSA cDNA. ${ }^{11}$ In China, a pharmaceutical excipient-grade rHSA from North China Pharmaceutical Company Ltd, expressed by Pichia pastoris, was approved by Chinese State Food and Drug Administration in 2011. ${ }^{12}$ In April of 2020, the phase I clinical study of Oryza sativa rHSA (OsrHSA), a recombinant HSA derived from rice grains, was completed in the clinical trial center of West Coast Clinical Trials (WCTT) global in United States. OsrHSA is the world's first plant-derived rHSA injection produced by Wuhan Healthgen Biotechnology Corp.

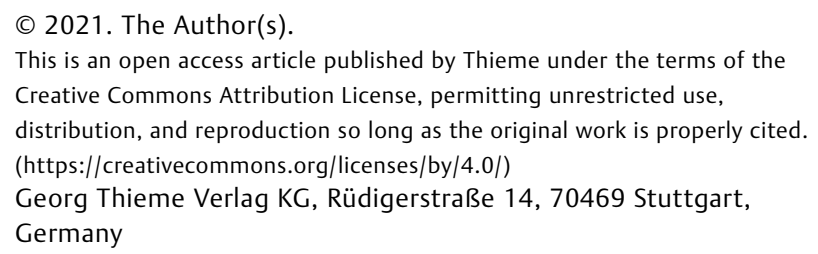


The results of phase I clinical trial showed that OsrHSA was safe and well-tolerated. ${ }^{13}$

Novel biotechnologies have allowed the expression of recombinant proteins (RPs) in the mammary glands of transgenic animals, among which two of the products have been approved for use in the clinic. In 2009, ATryn (antithrombin $\alpha$ ) from GTC Biotherapeutics became the first recombinant pharmaceutical approved by Food and Drug Administration (FDA), which was expressed in the milk of transgenic goats. ${ }^{14}$ The second was a C1 esterase inhibitor from Pharming Group N.V. It is expressed in the milk of transgenic rabbits ${ }^{15}$ and was approved by European Medicines Agency in 2010 and FDA in 2014. With the above achievements, the expression of rHSA in the milk of transgenic livestock becomes an attractive way to obtain a safe, easily scalable, and cost-effective source of clinically required HSA. To achieve specific expression of rHSA in mammary gland, promoters and regulatory regions from proteins that are specifically expressed in the mammary gland during lactation are usually introduced. ${ }^{16}$ Promoters of sheep $\beta$-lactoglobulin $\left(\beta\right.$-LG), ${ }^{17}$ goat $\beta$-LG, ${ }^{18,19}$ and mouse whey acidic protein (mWAP) ${ }^{20,21}$ have been reported to guide the expression of rHSA in the milk of transgenic mice and the expression level of rHSA varies from 0.001 to $11.95 \mathrm{~g} / \mathrm{L}$.

In this study, we used bovine $\alpha_{\mathrm{s} 1}$-casein promoter to express rHSA in the milk of transgenic mice. We aimed to investigate the ability of bovine $\alpha_{\mathrm{s} 1}$-casein promoter to guide rHSA expression in mammary gland and expand the potential for large-scale, cost-effective manufacture of rHSA in transgenic animals.

\section{Materials and Methods}

\section{Animals}

BALB/c mice were purchased from SLAC Laboratory Animal Co., Ltd (Shanghai, China) and were housed in specificpathogen free barrier facilities. All animal experiments were approved by the Animal Ethical Committee at Shanghai Institute of Pharmaceutical Industry, which was conformed to the National Institutes of Health Guidelines on Laboratory Research and Guide for the Care and Use of Laboratory Animals (8th edition, 2011).

\section{Construction of the rHSA Expression Vector}

An HSA expression cassette was constructed as shown in - Fig. 1. HSA minigene (cDNA of HSA with its intron 1) was synthesized according to the GenBank (NCBI accession number: AF542069). The HSA minigene was infused into the
ClaI-Sall digested plasmid 807 (kindly provided by Pharming Group N.V., which contains a $2 \times$ chicken $\beta$-globin insulator, a bovine $\alpha_{\mathrm{s} 1}$-casein promoter, and $\alpha \mathrm{s} 1$-casein $3^{\prime}$ flank sequences) by an In-Fusion HD Cloning System (Takara, Beijing, China). The primers used for vector construction are listed in -Table $\mathbf{1}$.

\section{Generation and Identification of Transgenic Mice}

The 23-kb HSA expression cassette including HSA minigene, $2 \times$ chicken $\beta$-globin insulator, a bovine $\alpha_{\mathrm{s} 1}$-casein promoter, and $\alpha_{\mathrm{s} 1}$-casein $3^{\prime}$ flank sequences were cleaved from the expression vector via NotI digestion. The purified DNA fragments were subsequently microinjected into pronucleus of zygotes derived from BALB/c mice according to standard protocols. Genomic DNA was extracted from tails of 7-day-old mice for transgene screening. Primers used in a multiplex polymerase chain reaction (PCR) system (Takara, Beijing, China) are listed in $\mathbf{- T a b l e ~} \mathbf{1}$. The reaction was processed under the following conditions: $94^{\circ} \mathrm{C}$ for 1 minute for predenaturation, $94^{\circ} \mathrm{C}$ for 30 seconds, $59^{\circ} \mathrm{C}$ for 30 seconds, and $72^{\circ} \mathrm{C}$ for 1 minute for 30 cycles, followed by a final extension at $72^{\circ} \mathrm{C}$ for 5 minutes. The transgene copy number in each transgenic mouse was determined following the protocols described in our previous report. ${ }^{22}$

\section{rHSA-Ectopic Transcription Analysis by RT-PCR}

Total RNA was isolated with TRIzol (Invitrogen, China) from mammary gland, liver, thymus, colon, kidney, stomach, uterus, lung, and heart of transgenic mice on day 8 of lactation according to the manufacturer's instructions. PrimeScript II RTase (Takara, Beijing, China) and oligo-dT primer were used to synthesize cDNA from $10 \mu \mathrm{g}$ RNA. PCR was then performed using HSA primer pairs HRT-5 and HRT-3 and actin primer pairs Actin-5 and Actin-3 (-Table 1), resulting in a 160 bp and a 263 bp products, respectively.

\section{Detection of rHSA Expression in Milk Samples}

Milk samples of both nontransgenic and transgenic mice were collected on the 8 th day of lactation after parturition. ${ }^{23}$ The milk sample was diluted 1:500 in phosphate-buffered saline (PBS) and defatted by centrifugation at $1,600 \mathrm{~g}$ for 20 minutes. Then $10 \mu \mathrm{L}$ diluted milk samples were loaded on the SDS-PAGE (sodium dodecyl-sulfate polyacrylamide gel electrophoresis) for Western blotting analysis. Milk from nontransgenic mice was used as the negative control while the HSA standard (Sigma, United States) was the positive control. After protein transfer, the $0.45 \mu \mathrm{m}$ PVDF membrane (Millipore, United States) was

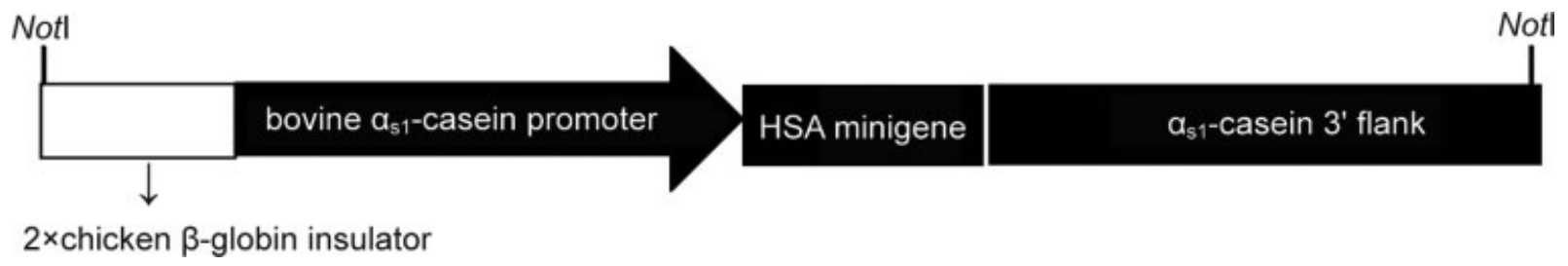

Fig. 1 Schematic structure of HSA minigene expression cassette. The expression cassette contains $2.4 \mathrm{~kb} 2 \times$ chicken $\beta$-globin insulator, $6.3 \mathrm{~kb}$ $\alpha_{\mathrm{s} 1}$-casein promoter, $2.3 \mathrm{~kb}$ HSA minigene, and $7.9 \mathrm{~kb} \alpha_{\mathrm{s} 1}$-casein $3^{\prime}$ flank sequences. The arrows indicate the direction of the transcription. HSA, human serum albumin. 
Table 1 Oligonucleotide primers used in this study

\begin{tabular}{|l|l|l|}
\hline Primer name & Oligonucleotide sequences $\left(\mathbf{5}^{\prime} \rightarrow \mathbf{3}^{\prime}\right)$ & Products \\
\hline 8Hmini-5 & TGATCATCAACCCATCGATGCCACCATGAAGTGGGTAACCT & $\begin{array}{l}\text { 2,539 bp HSAmini gene full length } \\
\text { for vector construction }\end{array}$ \\
\hline 8Hmini-3 & GTCCCTCAGAATTCGTCGACTTATAAGCCTAAGGCAGCTTGAC & \\
\hline HMP-5 & TCTTTAGCTCGGCTTATTCC & $\begin{array}{l}1,300 \text { bp fragment of HSA minigene } \\
\text { for multiple PCR }\end{array}$ \\
\hline HMP-3 & GTTCATCGAGCTTTGGCAAC & \\
\hline CAS450-5 & TGGTGGATACACTCCTTTGCAT & $\begin{array}{l}450 \text { bp casein promoter fragment } \\
\text { for multiple PCR }\end{array}$ \\
\hline CAS450-3 & CTGTTCAGGCTGTCCACTTTGA & \\
\hline ACtin-5 & GAGACCTTCAACACCCCAGC & 263 bp actin fragment for multiple PCR \\
\hline Actin-3 & ATGTCACGCACGATTTCCC3 & 160 bp fragment of HSA minigene for RT-PCR \\
\hline HRT-5 & TGTGAAGTCTTACAAGGTTATC & \\
\hline HRT-3 & TCTTCAACCCTATTCTGTGA & \\
\hline
\end{tabular}

Abbreviations: HSA, human serum albumin; PCR, polymerase chain reaction.

blocked for 1 hour at room temperature (r.t.) in blocking buffer (TBS containing $0.2 \%$ Tween-20 and $5 \%$ nonfat milk powder). Monoclonal mouse anti-HSA antibody (Proteintech, China) diluted 1:1,000 in blocking buffer was used as the primary antibody and was incubated with the membrane for 1 hour at r.t. The membrane was then incubated with horseradish peroxidase (HRP)-conjugated goat anti-mouse antibody (Beyotime, Shanghai, China) (diluted at 1:1,000 in blocking buffer) for 1 hour at r.t. Electrochemiluminescence western blotting substrate (ThermoScientific, United States) was used for detection.

\section{Enzyme-Linked Immunosorbent Assay for HSA Concentration Determination}

The concentration of HSA in the milk of transgenic mice was determined by a human albumin ELISA (enzyme-linked immunosorbent assay) kit (RayBio, United States) according to the user's manual.

\section{Results}

\section{Generation of HSA Transgenic Mice}

The rHSA expression cassette was cleaved from the vector by NotI digestion. About $15 \mathrm{ng}$ of such fragment was microinjected into 359 fertilized BALB/c mouse eggs which were then reimplanted into pseudopregnant female mice $(n=8)$. The microinjection was stopped until the size of fertilized mouse eggs was enlarged by approximately 1.5 times. Female mice $(n=6)$ were pregnant and gave birth to 28 mice, 8 of which were transgenic positive as determined by multiplex PCR. - Fig. 2 shows that there were three PCR products obtained from DNA samples of the eight founders, namely a 263-bp fragment of actin, a 450-bp fragment of bovine $\alpha_{\mathrm{s} 1^{-}}$ casein promoter, and a 1,300-bp fragment of HSAmini gene. However, in nontransgenic and wild-type (WT) samples, only the 263-bp fragment of actin was amplified.

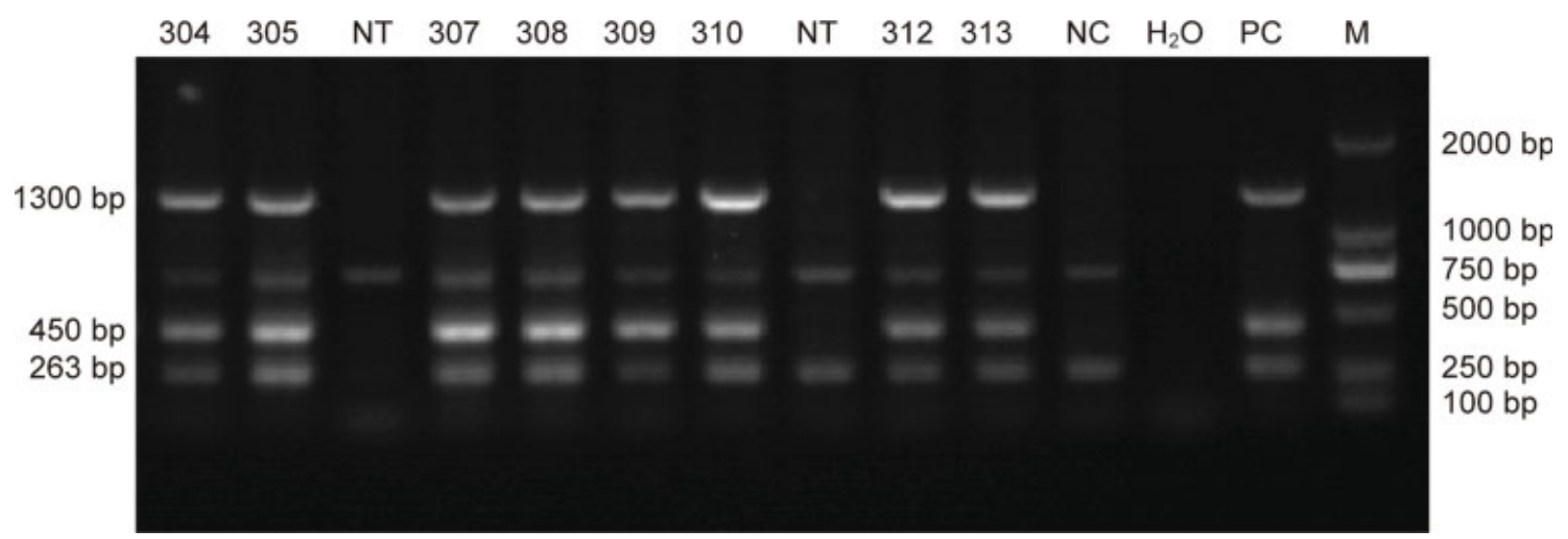

Fig. 2 Identification of transgenic mice by multiplex PCR. DNA extracted from 7-day-old mouse tail was used as the template for multiplex PCR. Mixtures of three pairs of primers (shown in - Table 1) were added to the multiplex PCR reaction system. Positive samples were recognized to be able to produce a 1,300 bp HSA minigene fragment, a 450 bp fragment of bovine $\alpha_{\mathrm{s} 1}$-casein promoter, and a 263 bp fragment of actin (indicated in the left). NT: non-transgenic mice. 304, 305, 307, 308, 309, 310, 312, 313: transgenic mice. $\mathrm{H}_{2} \mathrm{O}: \mathrm{H}_{2} \mathrm{O}$ as the template. NC: negative control, genome DNA extracted from wild-type mouse. PC: positive control-plasmid containing the HSA minigene expression cassette as a template. M: marker DL2000 (Takara, Beijing, China). HSA, human serum albumin; PCR, polymerase chain reaction. 
Table 2 The copy number of the F0 founders

\begin{tabular}{|l|l|l|l|l|l|l|l|l|}
\hline $\begin{array}{l}\text { F0 } \\
\text { founders }\end{array}$ & 304 & 305 & 307 & 308 & 309 & 310 & 312 & 313 \\
\hline $\begin{array}{l}\text { Transgene } \\
\text { copy } \\
\text { number }\end{array}$ & 8 & 12 & 5 & 1 & 2 & 7 & 2 & 1 \\
\hline
\end{tabular}

The copy number of the eight F0 founders was detected by absolute quantitative PCR with the 3D Digital PCR technology, with the results shown in - Table 2. Four founders with relatively high copy number were bred with WT BALB/c mice to yield F1 generations. Multiplex PCR and copy number determination were conducted for both F0 and F1 generations. Positive female F1 transgenic mice (304-10, 305-12, 307-1, $308-1,309-8,310-5,312-2,313-10)$ containing the same copy number with the F0 founders were selected to be impregnated for the milk collection.

\section{rHSA Transcription Specificity in Different Tissues}

rHSA transcription specificity was analyzed by reverse transcription PCR (RT-PCR) from nine different tissues including mammary gland, stomach, lung, heart, liver, thymus, colon, kidney, and uterus. Tissues were isolated from an F1 female transgenic mouse 305-12 on the 10th day of lactation. As shown in - Fig. 3, strong transcription of rHSA was found in the mammary gland with no HSA transcription in other eight tissues. Similar results were obtained in F1 female transgenic mice from other four lines $(304,307,310,312$; data not shown).

The Expression of rHSA in the Milk of Transgenic Mice Milk was collected from eight positive female F1 transgenic mice (304-10, 305-12, 307-1, 308-1, 309-8, 310-5, 312-2, $313-10)$ on the 8 th day of lactation. The F1 transgenic mice selected for milk analysis contained the same copy number with its corresponding FO founders. Milk from a female WT $\mathrm{BALB} / \mathrm{c}$ mouse was used as the negative control and HSA standard as a positive control. In addition, $15 \mu \mathrm{L}$ milk samples with a dilution of 1:500 in PBS and 50 ng standard HSA were loaded on the SDS-PAGE for Western blotting analysis. After incubation with a monoclonal HRP-conjugated goat antimouse antibody, a band with a molecular weight of $\sim 66 \mathrm{kDa}$, the size of HSA standard, was observed in all positive transgenic mouse milk samples, indicating an expression of rHSA in the mammary gland of transgenic mice. No band was found in the milk sample from the WT BALB/c mouse (-Fig. 4). No significant signals were detected in transgenic lines 308 and 309, and a very weak signal in 313.

Since no signal was detected in transgenic F1 from transgenic lines 308 and 309, and a weak signal in 313 by Western blotting, the expression level of rHSA in the milk of transgenic F1 female mice from transgenic lines 304, 305, 307, 310, 312, and female WT mice was measured by ELISA according to the manufacturer's instructions. The concentration of rHSA from different transgenic mice is listed in - Table 3. The highest level detected was $1.98 \pm 0.12 \mathrm{~g} / \mathrm{L}$ in the transgenic line of 304.

\section{Discussion}

To meet the growing demand for HSA in the clinic, many efforts have been made in past decades to express rHSA in different hosts as alternatives of plasma-derived HSA. rHSA has been successfully expressed in bacteria, ${ }^{7}$ yeast, ${ }^{8}$ plants, ${ }^{9}$ and animals. ${ }^{10}$ The earliest host to be used to produce rHSA was Escherichia coli which is currently the most common expression system for a great number of RPs. ${ }^{24}$ Most rHSA expressed in E. coli was insoluble and in the form of inclusion body, which may be due to aggregation of overexpressed protein and lack of proper folding in the cytoplasm. ${ }^{25}$ Sharma and Chaudhuri ${ }^{7}$ have optimized the cell growth conditions during protein production in $E$. coli and obtained an enhanced ( $\sim 60 \%)$ expression of soluble rHSA and an increased activity compared with the original process condition. Various species including $S$. cerevisiae, ${ }^{26-28}$ Hansenula polymorpha, ${ }^{29-31}$ Kluyveromyces lactis, ${ }^{32-34}$ and

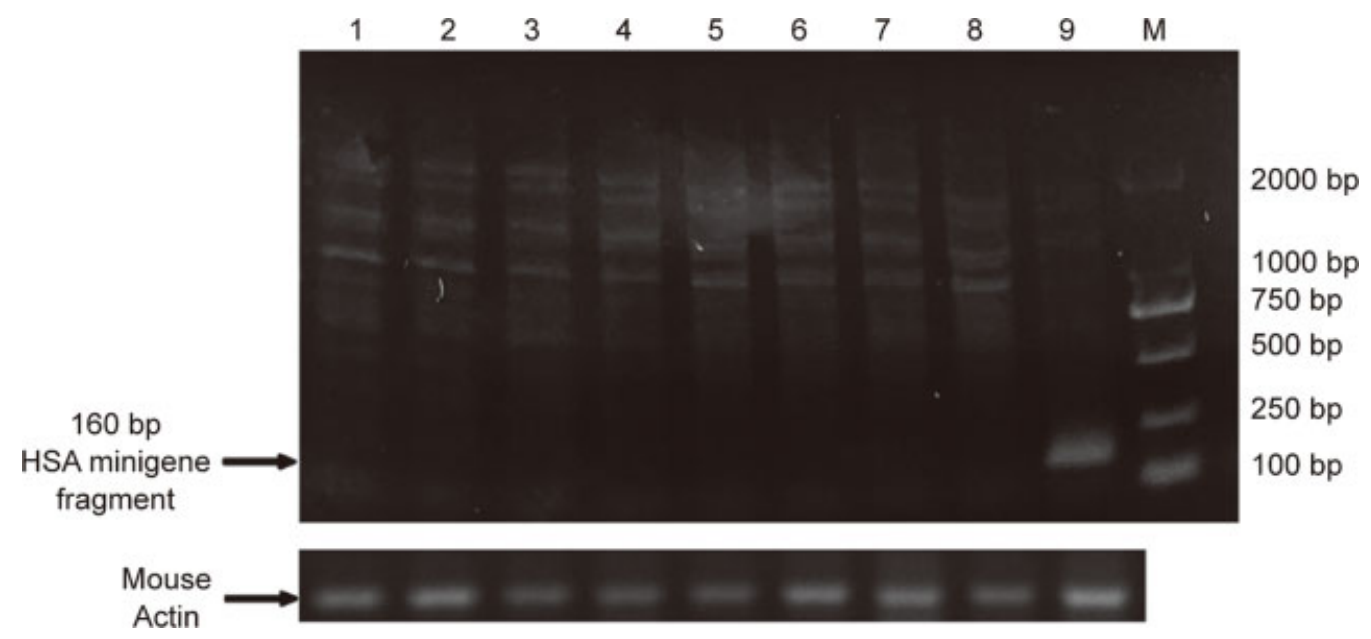

Fig. 3 rHSA transcription specificity in mammary gland. cDNA of different tissues was synthesized after RNA was extracted from liver, thymus, colon, kidney, stomach, uterus, lung, heart, and mammary gland (lanes 1-9) of the F1 transgenic female mouse on day 10 of lactation. HRT-5 and HRT-3 primers were used in RT-PCR to detect a product of $160 \mathrm{bp}$ which was clearly and specifically found in cDNA of mammary gland. A $263 \mathrm{bp}$ actin fragment was amplified as an internal control. rHSA, recombinant human serum albumin. 


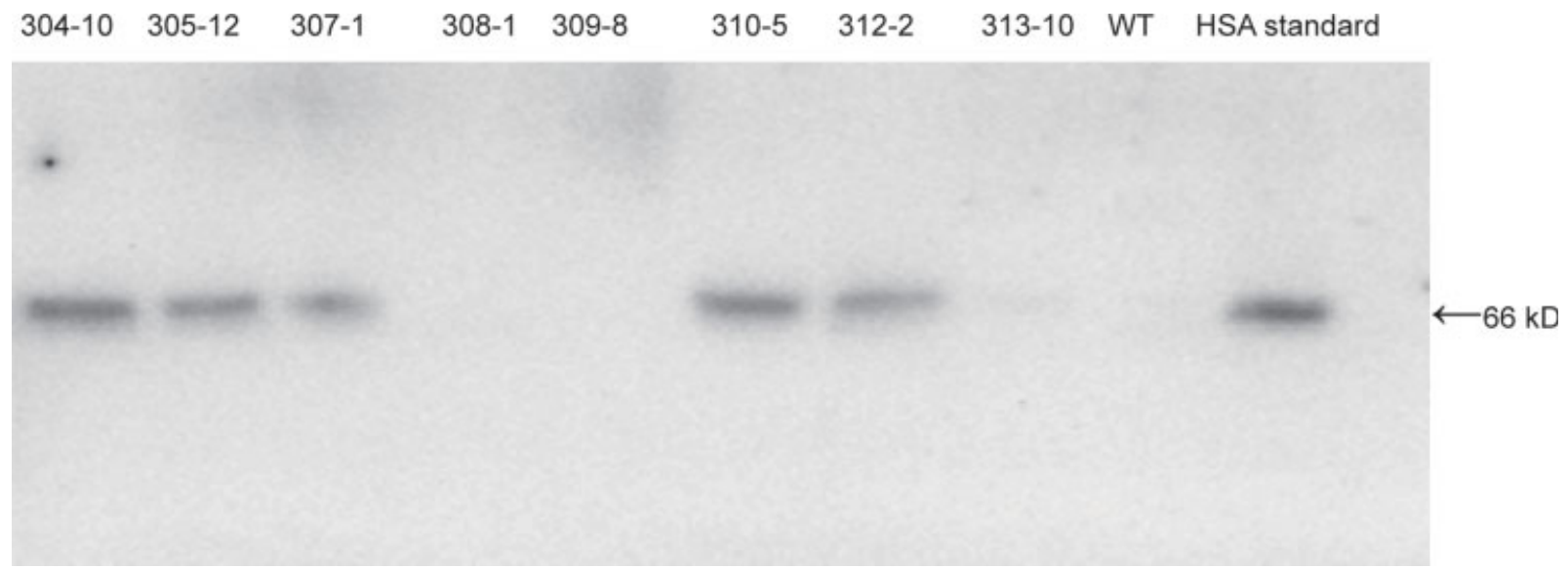

Fig. 4 Detection of rHSA expression in transgenic mice by Western blotting. The skimmed milk samples from different mice were diluted at 1:500 in PBS and separated on a 10\% SDS-PAGE. Lanes 304-313: milk samples of transgenic F1 generation from different transgenic mouse lines. WT: milk from WT mice. A monoclonal mouse-anti-human albumin was used as the first antibody diluting at 1:1,000. rHSA, recombinant human serum albumin; WT, wild type.

Table 3 Concentration of rHSA in the milk of different transgenic mice

\begin{tabular}{|l|l|l|}
\hline F0 founders & $\begin{array}{l}\text { F1 female } \\
\text { mice }\end{array}$ & $\begin{array}{l}\text { rHSA expression } \\
\text { level in milk (g/L) }\end{array}$ \\
\hline 304 & $304-10$ & $1.98 \pm 0.12$ \\
\hline 305 & $305-12$ & $1.53 \pm 0.11$ \\
\hline 307 & $307-1$ & $1.49 \pm 0.08$ \\
\hline 310 & $310-5$ & $1.75 \pm 0.11$ \\
\hline 312 & $312-2$ & $1.32 \pm 0.08$ \\
\hline
\end{tabular}

Abbreviation: rHSA, recombinant human serum albumin. Note: Milk was collected from F1 transgenic females on the 8th day of lactation and defatted before the test. ELISA test was conducted following the protocols in the kit (Catalog \#: ELH-Albumin, RayBio, United States). Each sample was tested in triplicate.

P. pastoris ${ }^{35-37}$ were constructed to express rHSA for industrial use. With the alcohol oxidase 2 (AOX2) promoter, a strong and strictly regulated promoter in yeast, $P$. pastoris became more attractive for industrial rHSA production. ${ }^{38}$ In our previous study, the expression level of rHSA in $P$. pastoris reached up to $8.8 \mathrm{~g} / \mathrm{L}$ in fermentation after optimization. ${ }^{8}$ Transgenic plants offer another way for rHSA expression, including tobacco leaves, ${ }^{39}$ potato tuber, ${ }^{40}$ and rice seed. ${ }^{41}$ He et al demonstrated a large-scale production of OsrHSA with a purity $>99 \%$ and a productivity rate of $2.75 \mathrm{~g} / \mathrm{kg}$ brown rice. ${ }^{42}$ The level of OsrHSA reached $10.58 \%$ of the total soluble protein of the rice grain. Recently, Sedaghati et al illustrated the transient expression of HSA gene in tobacco leaves by agroinfiltration, which highly depends on tobacco genotypes, Agrobacterium strains used for cotransfection, and harvesting time. ${ }^{9}$ With the ability to ensure correct posttranslational modifications for RPs, the mammary gland of transgenic animals has become a promising alternative bioreactor for the production of RPs, including rHSA. rHSA was successfully expressed in the milk of mice with expression levels vary from 0.002 to $11.9 \mathrm{~g} / \mathrm{L}^{6}{ }^{6}$ Wu et al have constructed a 37-kb mWAP-genomic HSA hybrid gene locus and obtained transgenic mice which expressed rHSA at an extremely high level of $11.9 \mathrm{~g} / \mathrm{L}^{21}$ Larger animals with higher production of milk such as goat ${ }^{43}$ and cattle ${ }^{19}$ were also used for rHSA production. Echelard et al have used a somatic cell nuclear transfer (SCNT) technique and developed a herd of transgenic cattle among which rHSAs express in the levels from 1 to $2 \mathrm{~g} / \mathrm{L}^{19}$

Typically, to express a RP in the milk of a transgenic animal, an expression vector containing a long 5 '-region (1-7 kb) with a promoter, enhancers that increase the expression of proteins in mammary glands, and a gene sequence encoding the targeted protein, is constructed. ${ }^{44}$ These promoters and regulatory regions come from genes coding for proteins that are specifically expressed in the mammary gland during lactation. ${ }^{44}$ Due to conservation between the transcriptional factors which regulate the production of milk proteins in mammary glands, promoters from one animal species usually can mediate effective transcription of the transgene in the mammary gland of another animal species. ${ }^{45}$ Until recently, various regulatory sequences of mammary gland-specific genes, such as WAP-promoter, $\alpha_{\mathrm{S} 1-}$ casein promoter, $\beta$-casein promoter, and $\beta$-lactoglobulin ( $\beta$-LG) promoter, have been isolated and verified in transgenic animals. ${ }^{46}$ Since bovine $\alpha_{s 1}$-casein is the most abundant protein in bovine milk, the bovine $\alpha_{\mathrm{s} 1}$-casein promoter has been widely used as a mammary-specific regulator to express a variety of RPs such as lactoferrin, ${ }^{47}$ lysozyme, ${ }^{48}$ and granulocyte colony-stimulating factor. ${ }^{49}$ For rHSA expression, mWAP and $\beta$-LG from sheep and goat were the most frequently used promoters in mice. However, approximately $50 \%$ of the transgenic lines controlled by the WAP and $\beta$-LG promoters failed to produce detectable levels of rHSA in the milk. ${ }^{20,50}$ Other regulatory elements such as insulators and 3'-untranslated region of a gene, which may contribute to mRNA transcription and stability, are also used in transgenic animals. ${ }^{51}$ The chicken $\beta$-globin insulator (HS4 insulator) with a length of $1200 \mathrm{bp}$ acts as a universal transcription regulator which can increase the activity of weak promoters. ${ }^{52}$ It has been reported that the HS4 insulator significantly increased the expression level of targeted protein in different transgenic animals. ${ }^{53-56}$

The widely used technique for the generation of transgenic animals needs microinjection of a transgene-containing DNA fragment into the pronucleus of a fertilized oocyte, which is then transplanted into a pseudopregnant mother. During this 
period, the transgene-containing DNA fragment is randomly integrated into the recipient genome via natural processes of genomic DNA breakage and repair. ${ }^{57}$ Therefore, the randomness of transgene integration and the uncontrolled variability in the number of transgene copies lead to a harboring selection of a large number of primary transgenic animals. Nowadays, several new technologies enabling transgenes to be integrated into a specific genomic site have been explored to obtain a transgenic line with effective production of targeted protein. New technologies among them are the SCNT technology, ${ }^{19}$ site-specific recombinases system, and site-specific nucleases system such as zinc finger nuclease, ${ }^{58}$ and transcription activator-like effector nuclease. ${ }^{59}$ With the rapid development of targeted genome editing technologies such as the CRISPR/Cas9 system, ${ }^{60}$ exogenous transgene expression in the milk and the use of transgenic animals as bioreactors have become increasingly more important and promising. It will make the transgenesis process more efficient and reduce the cost of the production of RPs. Besides the use of these new technologies, selection of different elements in the expression cassette is also an alternative way to improve rHSA expression in transgenic animals, including the selection of different promoters and the use of HS4 insulator, which acts as a barrier and protects a gene against chromosomal position effects. ${ }^{61}$

In this study we have demonstrated the feasibility of using bovine $\alpha_{\mathrm{s} 1}$-casein promoter to induce the expression of human rHSA in transgenic mice. Therefore, the regulatory elements for controlling HSA expression in transgenic animals were expanded beyond those already reported promoters such as mWAP ${ }^{20}$ and $\beta$-LG from sheep and goat. ${ }^{50}$ Concerning protein expression in transgenic animals, the required quantity of the protein and the reproductive capacity of the animals should be considered for the selection of transgenic animals. ${ }^{62}$ Transgenic mice are a good choice to test expression constructs prior to the generation of larger founder transgenic animals because of a shorter period of reproductive maturity, less time taken between generations, and more numbers of offspring. ${ }^{63}$ Meanwhile, existence of adverse effects on the health of animals caused by expressed heterogeneous protein can be determined by transgenic mice in a relatively inexpensive and rapid manner. However, the small amount of milk derived from transgenic mice limited the expression of RPs to milligram levels. ${ }^{64}$ Here, we used transgenic mice as a model to illustrate the expression of human rHSA under the control of bovine $\alpha_{s 1}{ }^{-}$ casein promoter. Our further aim is to express human rHSA for production using this regulatory element in larger transgenic animals. Our effort helps to provide a convincing evidence for this promoter using in rHSA production in larger transgenic animals such as rabbits, sheep, and cows, which have much higher production of milk than mice.

In this study we have constructed an rHSA expression cassette which contained CDNA and intron 1 of HSA gene under the control of the bovine $\alpha_{s 1}$-casein promoter. The involvement of introns in a transgene is generally considered as a way of increasing the transgene expression level. ${ }^{65}$ In some cases, the use of a minigene increases the transgene expression level in comparison with the use of cDNA. This also reduces the overall size of the genetic construct compared with a full-length transgene copy. ${ }^{17}$ Therefore, in this study we synthesized an HSA minigene which contains the cDNA of HSA and an intron 1. A $2 \times$ chickenglobin insulator was added upstream of the promoter as a transcription enhancer, while a $7.9 \mathrm{~kb} \alpha_{\mathrm{s} 1}$-casein 3' flank sequence was used to strengthen the transcription termination located at the downstream of the expression cassette. Since the bovine $\alpha_{\mathrm{s} 1}$-casein promoter has been used to express several proteins in different transgenic animals besides mice, here we chose transgenic mice as a model system to demonstrate the expression of rHSA using the bovine $\alpha_{\mathrm{s} 1}$-casein promoter as the regulatory element. The addition of HS4 insulator to the expression cassette is another strategy for improving HSA expression. As shown in the result, rHSA was successfully detected in the milk of transgenic-positive mice. RT-PCR showed rHSA expression only in the mammary gland, indicating the tissue specificity of the bovine $\alpha_{\mathrm{s} 1}$-casein promoter in directing transgene transcription in transgenic mice. The highest expression level of rHSA detected by ELISA was $1.98 \pm 0.12 \mathrm{~g} / \mathrm{L}$, comparable with the rHSA expression level reported. Although such expression level is not the highest among those reported in transgenic mice, a higher rHSA level is possible to achieve through more selection of transgenic mice. No and very weak signals were detected in three lines with a low copy number. The highest expression level of rHSA was detected in a line with transgene copy number of 7 but not the highest copy number of 12 , and in this study, we found that the difference in expression level among transgenic mice was less obvious than that was detected in copy numbers. Such results suggested that a high copy number may not be a necessary factor for a high expression level of the RPs in transgenic mice. Other factors such as integration sites of foreign fragments, the interaction between foreign fragments and genome DNA, and the interaction between regulatory elements in the expression cassette and the regulatory elements in mice genome may also affect the expression level of rHSA in transgenic mice. Overall, our results suggest the ability of the bovine $\alpha_{\mathrm{s} 1}$-casein promoter to induce successful expression of rHSA in the mammary gland of transgenic mice.

\section{Conclusion}

In conclusion, we have obtained transgenic mice that produce rHSA in the milk under the control of the bovine $\alpha_{s 1}$-casein promoter. The rHSA expression is tissue-specific, which only occurs in the mammary gland. Our strategy of rHSA expression construct provides an alternative of successful expressions of rHSA, and probably other RPs, in the mammary glands of transgenic mice.

\section{Funding}

This work was supported by Sinopharm New Product Development Foundation (Grant No. 2013SW28).

Conflict of Interest

All authors declare no conflict of interest. 


\section{References}

1 Minghetti PP, Ruffner DE, Kuang WJ, et al. Molecular structure of the human albumin gene is revealed by nucleotide sequence within q11-22 of chromosome 4. J Biol Chem 1986;261(15): 6747-6757

2 Alexander MR, Alexander B, Mustion AL, Spector R, Wright CB. Therapeutic use of albumin: 2. JAMA 1982;247(06):831-833

3 Bertucci C, Pistolozzi M, De Simone A. Circular dichroism in drug discovery and development: an abridged review. Anal Bioanal Chem 2010;398(01):155-166

4 Furukawa M, Tanaka R, Chuang VT, et al. Human serum albuminthioredoxin fusion protein with long blood retention property is effective in suppressing lung injury. J Control Release 2011;154 (02):189-195

5 Komatsu T, Qu X, Ihara H, Fujihara M, Azuma H, Ikeda H. Virus trap in human serum albumin nanotube. J Am Chem Soc 2011;133 (10):3246-3248

6 Chen Z, He Y, Shi B, Yang D. Human serum albumin from recombinant DNA technology: challenges and strategies. Biochim Biophys Acta 2013;1830(12):5515-5525

7 Sharma A, Chaudhuri TK. Revisiting Escherichia coli as microbial factory for enhanced production of human serum albumin. Microb Cell Fact 2017;16(01):173

8 Zhu W, Gong G, Pan J, et al. High level expression and purification of recombinant human serum albumin in Pichia pastoris. Protein Expr Purif 2018;147:61-68

9 Sedaghati B, Haddad R, Bandehpour M. Transient expression of human serum albumin (HSA) in tobacco leaves. Mol Biol Rep 2020;47(09):7169-7177

10 Houdebine LM. Production of pharmaceutical proteins by transgenic animals. Comp Immunol Microbiol Infect Dis 2009;32(02): 107-121

11 Mead D, Person D, Devine M. Recombinant human albumin: applications as a biopharmaceutical excipient. Innov Pharm Technol 2007;22:42-44

12 North China Pharmaceutical Group. New Drug Research and Development Co. Ltd. successfully developed recombinant human serum albumin and obtained SFDA approval [in Chinese]. Accessed September 23, 2011 at: https://health.sohu.com/ 20110923/n320317439.shtml

13 Heavy news: Healthgen Biotechnology Cl., Ltd. has successfully completed the phase I clinical study of its plant derived-recombination human serum albumin injection in the United States [in Chinese]. Accessed April 2, 2020 at: http://www.phirda.com/artilce_21750.html

14 Adiguzel C, Iqbal O, Demir M, Fareed J. European community and US-FDA approval of recombinant human antithrombin produced in genetically altered goats. Clin Appl Thromb Hemost 2009;15 (06):645-651

15 Varga L, Farkas H. rhC1INH: a new drug for the treatment of attacks in hereditary angioedema caused by $\mathrm{C} 1$-inhibitor deficiency. Expert Rev Clin Immunol 2011;7(02):143-153

16 Clark AJ. The mammary gland as a bioreactor: expression, processing, and production of recombinant proteins. J Mammary Gland Biol Neoplasia 1998;3(03):337-350

17 Shani M, Barash I, Nathan M, et al. Expression of human serum albumin in the milk of transgenic mice. Transgenic Res 1992;1 (05):195-208

18 Barash I, Faerman A, Baruch A, Nathan M, Hurwitz DR, Shani M. Synthesis and secretion of human serum albumin by mammary gland explants of virgin and lactating transgenic mice. Transgenic Res 1993;2(05):266-276

19 Echelard Y, Williams JL, Destrempes MM, et al. Production of recombinant albumin by a herd of cloned transgenic cattle. Transgenic Res 2009;18(03):361-376

20 Barash I, Faerman A, Richenstein M, et al. In vivo and in vitro expression of human serum albumin genomic sequences in mammary epithelial cells with beta-lactoglobulin and whey acidic protein promoters. Mol Reprod Dev 1999;52(03):241-252

$21 \mathrm{Wu} \mathrm{X}$, Lin Y, Xiong F, et al. The extremely high level expression of human serum albumin in the milk of transgenic mice. Transgenic Res 2012;21(06):1359-1366

22 Gong G, Zhang W, Xie L, Xu L, Han S, Hu Y. Expression of a recombinant anti-programed cell death 1 antibody in the mammary gland of transgenic mice. Prep Biochem Biotechnol 2021;51 (02):183-190

23 DePeters EJ, Hovey RC. Methods for collecting milk from mice. J Mammary Gland Biol Neoplasia 2009;14(04):397-400

24 Lawn RM, Adelman J, Bock SC, et al. The sequence of human serum albumin cDNA and its expression in E. coli. Nucleic Acids Res 1981;9(22):6103-6114

25 Lobstein J, Emrich CA, Jeans C, Faulkner M, Riggs P, Berkmen M. SHuffle, a novel Escherichia coli protein expression strain capable of correctly folding disulfide bonded proteins in its cytoplasm. Microb Cell Fact 2012;11:56

26 Kerry-Williams SM, Gilbert SC, Evans LR, Ballance DJ. Disruption of the Saccharomyces cerevisiae YAP3 gene reduces the proteolytic degradation of secreted recombinant human albumin. Yeast 1998;14(02):161-169

27 Kang HA, Choi ES, Hong WK, et al. Proteolytic stability of recombinant human serum albumin secreted in the yeast Saccharomyces cerevisiae. Appl Microbiol Biotechnol 2000;53(05):575-582

28 Cheperegin SE, Efremov BD, Kozlov DG. Precipitation of human serum albumin from yeast culture liquid at $\mathrm{pH}$ values below 5 . Protein Expr Purif 2010;72(02):205-208

29 Cox H, Mead D, Sudbery P, Eland RM, Mannazzu I, Evans L. Constitutive expression of recombinant proteins in the methylotrophic yeast Hansenula polymorpha using the PMA1 promoter. Yeast 2000;16(13):1191-1203

30 Kang HA, Kang W, Hong WK, et al. Development of expression systems for the production of recombinant human serum albumin using the MOX promoter in Hansenula polymorpha DL-1. Biotechnol Bioeng 2001;76(02):175-185

31 Heo JH, Hong WK, Cho EY, et al. Properties of the Hansenula polymorpha-derived constitutive GAP promoter, assessed using an HSA reporter gene. FEMS Yeast Res 2003;4(02):175-184

32 Fleer R, Yeh P, Amellal N, et al. Stable multicopy vectors for highlevel secretion of recombinant human serum albumin by Kluyveromyces yeasts. Biotechnology (N Y) 1991;9(10):968-975

33 Blondeau K, Boze H, Jung G, Moulin G, Galzy P. Physiological approach to heterologous human serum albumin production by Kluyveromyces lactis in chemostat culture. Yeast 1994;10(10): 1297-1303

34 Lodi T, Neglia B, Donnini C. Secretion of human serum albumin by Kluyveromyces lactis overexpressing KIPDI1 and KIERO1. Appl Environ Microbiol 2005;71(08):4359-4363

35 Kobayashi K, Kuwae S, Ohya T, et al. High-level expression of recombinant human serum albumin from the methylotrophic yeast Pichia pastoris with minimal protease production and activation. J Biosci Bioeng 2000;89(01):55-61

36 Kobayashi K, Kuwae S, Ohya T, Ohda T, Ohyama M, Tomomitsu K. High level secretion of recombinant human serum albumin by fed-batch fermentation of the methylotrophic yeast, Pichia pastoris, based on optimal methanol feeding strategy. J Biosci Bioeng 2000;90(03):280-288

37 Qiu RD, Li SY, Chen JG, Wu XF, Yuan ZY. High expression and purification of recombinant human serum albumin from Pichia pastoris. Sheng Wu Hua Xue Yu Sheng Wu Wu Li Xue Bao (Shanghai) 2000;32(01):59-62

38 Ohi H, Miura M, Hiramatsu R, Ohmura T. The positive and negative cis-acting elements for methanol regulation in the Pichia pastoris AOX2 gene. Mol Gen Genet 1994;243(05):489-499

39 Sijmons PC, Dekker BM, Schrammeijer B, Verwoerd TC, van den Elzen PJ, Hoekema A. Production of correctly processed human 
serum albumin in transgenic plants. Biotechnology (N Y) 1990;8 (03):217-221

40 Farran I, Sánchez-Serrano JJ, Medina JF, Prieto J, Mingo-Castel AM. Targeted expression of human serum albumin to potato tubers. Transgenic Res 2002;11(04):337-346

41 Zhang Q, Yu H, Zhang FZ, Shen ZC. Expression and purification of recombinant human serum albumin from selectively terminable transgenic rice. J Zhejiang Univ Sci B 2013;14(10):867-874

42 He Y, Ning T, Xie T, et al. Large-scale production of functional human serum albumin from transgenic rice seeds. Proc Natl Acad Sci U S A 2011;108(47):19078-19083

43 Shuzhen H, Shuxiang X, Wei C. Human serum albumin (hALB) transient expression in goat milk after direct transfer of hALB expressing vector into mammary gland. Chin J Vet Sci 2000;20(05):419-422

44 Maga EA, Murray JD. Mammary gland expression of transgenes and the potential for altering the properties of milk. Biotechnology (N Y) 1995;13(13):1452-1457

45 Shepelev MV, Kalinichenko SV, Deykin AV, Korobko IV. Production of recombinant proteins in the milk of transgenic animals: current state and prospects. Acta Naturae 2018;10(03):40-47

46 Maksimenko OG, Deykin AV, Khodarovich YM, Georgiev PG. Use of transgenic animals in biotechnology: prospects and problems. Acta Naturae 2013;5(01):33-46

47 Platenburg GJ, Kootwijk EP, Kooiman PM, et al. Expression of human lactoferrin in milk of transgenic mice. Transgenic Res 1994;3(02):99-108

48 Maga EA, Shoemaker CF, Rowe JD, Bondurant RH, Anderson GB, Murray JD. Production and processing of milk from transgenic goats expressing human lysozyme in the mammary gland. J Dairy Sci 2006;89(02):518-524

49 van Berkel PH, Welling MM, Geerts M, et al. Large scale production of recombinant human lactoferrin in the milk of transgenic cows. Nat Biotechnol 2002;20(05):484-487

50 Huang Y, Huang Y, Huang Z. High expression of human serum albumin in milk of transgenic mice directed by the goat $\beta$-casein gene promoter region. Chin Sci Bull 2001;46:582-585

51 Wilkie GS, Dickson KS, Gray NK. Regulation of mRNA translation by $5^{\prime}-$ and 3'-UTR-binding factors. Trends Biochem Sci 2003;28 (04):182-188
52 Chung JH, Bell AC, Felsenfeld G. Characterization of the chicken beta-globin insulator. Proc Natl Acad Sci U S A 1997;94(02): 575-580

53 Giraldo P, Martínez A, Regales L, et al. Functional dissection of the mouse tyrosinase locus control region identifies a new putative boundary activity. Nucleic Acids Res 2003;31(21):6290-6305

54 Giraldo P, Rival-Gervier S, Houdebine LM, Montoliu L. The potential benefits of insulators on heterologous constructs in transgenic animals. Transgenic Res 2003;12(06):751-755

55 Rival-Gervier S, Pantano T, Viglietta C, et al. The insulator effect of the 5'HS4 region from the beta-globin chicken locus on the rabbit WAP gene promoter activity in transgenic mice. Transgenic Res 2003;12(06):723-730

56 Goldman IL, Georgieva SG, Gurskiy YG, et al. Production of human lactoferrin in animal milk. Biochem Cell Biol 2012;90(03): 513-519

57 Smith K. Theoretical mechanisms in targeted and random integration of transgene DNA. Reprod Nutr Dev 2001;41(06):465-485

58 Bogdanove AJ, Voytas DF. TAL effectors: customizable proteins for DNA targeting. Science 2011;333(6051):1843-1846

59 Silva G, Poirot L, Galetto R, et al. Meganucleases and other tools for targeted genome engineering: perspectives and challenges for gene therapy. Curr Gene Ther 2011;11(01):11-27

60 Nemudryi AA, Valetdinova KR, Medvedev SP, Zakian SM. TALEN and CRISPR/Cas genome editing systems: tools of discovery. Acta Naturae 2014;6(03):19-40

61 Wilson C, Bellen HJ, Gehring WJ. Position effects on eukaryotic gene expression. Annu Rev Cell Biol 1990;6:679-714

62 Echelard Y. Recombinant protein production in transgenic animals. Curr Opin Biotechnol 1996;7(05):536-540

63 Kumar TR, Larson M, Wang H, McDermott J, Bronshteyn I. Transgenic mouse technology: principles and methods. Methods Mol Biol 2009;590:335-362

64 Velander WH, Page RL, Morcöl T, et al. Production of biologically active human protein $\mathrm{C}$ in the milk of transgenic mice. Ann N Y Acad Sci 1992;665:391-403

65 Palmiter RD, Sandgren EP, Avarbock MR, Allen DD, Brinster RL. Heterologous introns can enhance expression of transgenes in mice. Proc Natl Acad Sci U S A 1991;88(02):478-482 